\title{
THE PERCEPTION OF SCHOOL STAFF AND PARENTS IN REGARD TO THE "ENFANT NATURE" APPROACH IN A QUEBEC PRESCHOOL
}

\author{
Élisabeth Lavallée ${ }^{1,2}$, Marie-Claude Rivard ${ }^{1,2}$, \& Claude Dugas ${ }^{1,3}$ \\ ${ }^{1}$ Department of Human Kinetics, Université du Québec à Trois-Rivières (Canada) \\ ${ }^{2}$ Groupe interdisciplinaire de recherche appliquée en santé (Canada) \\ ${ }^{3}$ Institut universitaire en déficience intellectuelle et en trouble du spectre de l'autisme (Canada)
}

\begin{abstract}
Despite the recognized benefits of outdoor free play on children's physical and psychological well-being, there is a marked decrease of the time spent in these activities. Many factors could explain this, notably early schooling, increased time spent in indoor sedentary activities and the rise of adults' supervision and concerns related to children's safety (Strife \& Downey, 2009). The Enfant Nature (EN) approach aims to counteract the "nature deficit disorder" (Louv, 2005) with an experiential outdoor education program. It also aims to foster overall children's development while promoting a healthy and active lifestyle. Over the course of a year, semi-structured interviews were conducted to explore the perceptions of school staff $(n=2)$ and parents $(n=8)$ of 4-year-olds in a preschool class engaged in EN approach. The experimental variables were perceptions related to the EN approach, the potential risk elements and the effects on the overall child's development. Our findings suggest that overall the participants demonstrated a high level of enthusiasm for EN and discovered a new stimulating way to learn and teach. They quickly concluded that the level of risk in a natural environment was similar to the school. They also reported that EN had been beneficial for children's cognitive, physical and social-emotional development, particularly for their self-confidence, general knowledge, problem solving, socialization, physical activity level and improvements of motor skills. The positive perceptions of EN and the recognition of its relevance for outdoor free play in learning allows us to be optimistic about the sustainability of this approach.
\end{abstract}

Keywords: Early childhood, outdoor learning, perception, school staff, parents.

\section{Introduction and context}

According to the Institut de la statistique du Québec (2013), 85.4\% of children have attended daycare before attending kindergarten. Knowing that these children spend about seven and a half hours each day at daycare, it represents nearly $65 \%$ of their daytime. Because of this societal reality, the physical and psychological well-being of preschoolers have become a shared responsibility between families and schools. Despite the fact that all children follow the same major developmental' stages in terms of physical, motor, cognitive/linguistic, social and emotional components, the pace can vary from one individual to another. Generally, children entering kindergarten have all the skills and abilities required to fully enjoy all the proposed educational activities. However, many children experience difficulties adjusting to the school's environment. In 2018, the Quebec Survey of Child Development in Kindergarten concluded that one out of four kindergarteners was considered vulnerable in at least one of the five domains of child development (Simard, Lavoie \& Audet, 2018). This knowledge is key since a vulnerable child is more likely to experience learning difficulties during his educational pathway. A child's level of development in kindergarten therefore seems to be associated with social adjustment and subsequent educational success (Cantin, Bouchard, \& Bigras, 2012). Thus, these issues raised some questions regarding the offer and effectiveness of services supporting child development dedicated to children and families.

Despite the recognized benefits of outdoor free play on children's development, there is a marked decrease in time spent in these activities. Many social factors could explain this, notably early schooling, increased time spent in indoor sedentary activities and the rise of adults' concerns related to children's safety (Strife \& Downey, 2009). The Enfant Nature (EN) approach aims to foster overall children's development while promoting a healthy and active lifestyle. This approach also aims to counteract the "nature deficit disorder" identified by Louv (2005) with an experiential outdoor education program, which is an innovative approach that is complementary to the educational program in Quebec. 


\section{Objectives and relevance of the study}

The objective of this study was to explore the evolution of the school staff and parents' perceptions about the EN approach. Using the current international literature, perceptions were evaluated according to the following variables: 1) the implementation of the EN approach, 2) the potential risk elements (physical and socio-emotional) and 3) the effects of the approach on the overall child's development. This kind of knowledge is essential for the success of an innovative project particularly in a school context. It will notably help to adjust the pedagogical content to ensure its quality and identify the elements to be maintained and/or improved. It will also provide useful information to ensure sustainability of the approach in Quebec.

\section{Method}

A descriptive qualitative study was used to achieve the research's objective. Over the course of a year, semi-structured interviews were conducted to explore the perceptions of school staff $(n=2)$ and parents $(\mathrm{n}=8)$ regarding the EN approach in a preschool class of 4-year-old children. Individual interviews were conducted with school staff as well as a focus group with parents.

To obtain an overall view of the perceptions over a school year, two interviews for each group were organized, one at the beginning of the school year and another one at the end of the year. For both groups, parents and school staff, the interview templates were organized in accordance to the three main variables identified in the literature. However, the structure of some questions differed between parents and school staff. Indeed, some questions for the parents were oriented towards their observations at home, while some questions for the school staff were oriented towards their role in nature and observations in class. The individual interviews lasted approximately 45 minutes and were structured using 17 questions; the focus groups lasted approximately 55 minutes and were structured using 14 questions.

The analysis strategy was based on the Boutin (2007) steps. The content was audio recorded, transcribed and analyzed using NVivo 11 software, which facilitates the categorization and classification by units of meaning. It also analyzes the similarities and differences noticed in the comments made by the participants.

\section{Findings and discussion}

According to the first variable, the level of openness and enthusiasm towards the EN approach was maintained over the school year for both groups of participants. Many factors contributed to the implementation success such as the planning level, the EN pedagogical material and the equipment provided to the children. One of the aspects that surprised the school staff was that the natural environment favoured improvements in positive behaviours, particularly in terms of linguistic skills, attitudes and initiative taking. In fact, Cameron-Faulkner, Melville, and Gattis (2018) recently demonstrated that natural environments influenced human communication. The two groups raised the same main challenge, namely to let children explore and experiment by themselves and suppress their need to overprotect them. The parents and school staff's openness towards the implementation of an alternative approach within the traditional program positively influenced their attitude.

Echoing to the second main variable, the discovery of the different types of activities involving risk-taking was always perceived in a positive way. Seasonal variations were seen as an asset in terms of exploration and learning opportunities rather than a barrier to outdoor activities. In addition, it appears that some factors alleviated participants' fears about potential risk such as environmental management, clarity of instructions and beneficial effects on children. It is important to note that the foundations of outdoor learning include risk-taking, not only for the pleasure of taking risks, but also for the benefits it can bring to children, particularly regarding developmental stages. According to Savery et al. (2016), the benefits outweigh the probability of any negative experience.

In relation to the effects, both groups of participants recognized that the EN approach promoted all spheres of child development. They also observed an increase in the duration and intensity of physical activity by children on a daily basis. The school staff pointed out that the outdoor activities that increased the level of physical activity had been beneficial for the classroom workshops, including activities of drawing, grabbing and cutting. Fjørtoft (2001) highlighted the relation between free play in the natural environment and the effects on children's motor skill. Regarding the small number of studies evaluating in a quantitative manner, the effects of natural environment on the development of gross and fine motor skills, further research is needed. The educational material, including stories and songs, have enabled children to acquire a wide range of knowledge about fauna and flora. Moreover, it allowed them to enrich their vocabulary and linguistic skills. The school staff explained that the outdoor activities had allowed 
the children to improve their problem-solving skills through various quests and challenges. Besides, Burdette and Whitaker (2005) argue that problem-solving opportunities, in a play context, promote the development of executive functions, which are important not only for subsequent educational success, but also for the achievement of everyday tasks. Both groups of participants indicated that EN had contributed to the development of several emotional skills and strengthened social ties, which was also reported by Strife and Downey (2009). Indeed, children were more resourceful, self-confident and autonomous in their actions.

\section{Conclusion}

Beyond this study, this innovative approach is part of a much broader focus considering that a child's level of development in kindergarten seems to be associated with social adjustment and subsequent educational success (Cantin et al., 2012). Since in Quebec one out of four children in kindergarten is vulnerable in at least one area of development, it is more than relevant to consider ways to optimize child development. The EN approach aims to promote global development, healthy lifestyles and educational success through active outdoor free play. It also encourages risk-taking by creating opportunities for children to push their physical, cognitive and social limits (Little \& Wyver, 2008). Although on a small scale, the results of this study demonstrated the potential benefits that this type of approach can have on the children's development. In addition, the participants' positive perceptions towards EN and the recognition of its relevance for active outdoor free play in learning allow us to be optimistic about the sustainability of this approach in Quebec.

\section{References}

Boutin, G. (2007). L'entretien de groupe en recherche et formation. Montréal: Éditions nouvelles.

Burdette, H. \& Whitaker, R. (2005). Resurrecting free play in young children: looking beyond fitness and fatness to attention, affiliation, and affect. Archives of Pediatrics and Adolescent Medecine, 159, 46-50. doi: 10.1001/archpedi.159.1.46

Cameron-Faulkner, T., Melville, J., \& Gattis, M. (2018). Responding to nature: Natural environments improve parent-child communication. Journal of Environmental Psychology, 59, 9-15. doi: $10.1016 /$ j.jenvp.2018.08.008

Cantin, G., Bouchard, C. \& Bigras, N. (2012). Les facteurs prédisposant à la réussite éducative dès la petite enfance. Revue des sciences de l'éducation, 38(3), 469-482. doi: 10.7202/1022708ar

Fjørtoft, I. (2001). The Natural Environment as a Playground for Children: The Impact of Outdoor Play Activities in Primary School Children. Early Childhood Education Journal, 29(2), 111-117. doi: 10.1023/A:1012576913074

Institut de la statistique du Québec (2013). Enquête québécoise sur le développement des enfants à la maternelle 2012. Retrieved from http://www.stat.gouv.qc.ca/statistiques/sante/enfantsados/developpement- enfants-maternelle-2012.pdf

Little, H. \& Wyver, S. (2008). Outdoor play: Does avoiding the risks reduce the benefits?. Australian Journal of Early Childhood, 33(2), 33-40.

Louv, R. (2005). Last child in the woods: saving our children from Nature-Deficit Disorder. Chapel Hill, $\mathrm{NC}$ : Algonquin Book.

Savery, A., Cain, T., Garner, J., Jones, T., Kynaston, E., Mould, K., . . . Wilson, D. (2016). Does engagement in Forest School influence perceptions of risk, held by children, their parents, and their school staff? Education 3-13: International Journal of Primary, Elementary and Early Years Education. doi: 10.1080/03004279.2016.1140799

Simard, M., Lavoie, A. \& Audet, N. (2018). Enquête québécoise sur le développement des enfants à la maternelle 2017: Portrait statistique pour le Québec et ses régions administratives. Québec. Retrieved from http://www.stat.gouv.qc.ca/statistiques/ sante/enfants-ados/developpement-enfantsmaternelle-2017.pdf

Strife, S. \& Downey, L. (2009). Childhood Development and Access to Nature: A New Direction for Environmental Inequality Research. Organization \& Environment, 22(1), 99-122. doi: $10.1177 / 1086026609333340$ 